\title{
Association between variations in the TLR4 gene and incident type 2 diabetes is modified by the ratio of total cholesterol to HDL-cholesterol
}

\author{
Melanie Kolz ${ }^{1}$, Jens Baumert ${ }^{1}$, Martina Müller ${ }^{1,2}$, Natalie Khuseyinova ${ }^{3}$, \\ Norman Klopp ${ }^{1}$, Barbara Thorand ${ }^{1}$, Christine Meisinger ${ }^{1,4}$, \\ Christian Herder ${ }^{5}$, Wolfgang Koenig*3 and Thomas Illig ${ }^{1}$
}

\begin{abstract}
Address: ${ }^{1}$ Institute of Epidemiology, Helmholtz Center Munich, German Research Center for Environmental Health, Neuherberg, Germany, ${ }^{2}$ Institute of Medical Information Processing, Biometry and Epidemiology, Ludwig-Maximilians-Universität, Munich, Germany, ${ }^{3}$ Department of Internal Medicine II-Cardiology, University of Ulm Medical Center, Ulm, Germany, ${ }^{4}$ Central Hospital of Augsburg, Germany and ${ }^{5}$ Institute for Clinical Diabetes Research, German Diabetes Center, Leibniz Center at Heinrich Heine University, Düsseldorf, Germany

Email: Melanie Kolz - melanie.kolz@helmholtz-muenchen.de; Jens Baumert - baumert@helmholtz-muenchen.de;

Martina Müller - martina.mueller@helmholtz-muenchen.de; Natalie Khuseyinova - natalie.khuseyinova@uniklinik-ulm.de; Norman Klopp - klopp@helmholtz-muenchen.de; Barbara Thorand - thorand@helmholtz-muenchen.de;

Christine Meisinger - christa.meisinger@helmholtz-muenchen.de; Christian Herder - christian.herder@ddfi.uni-duesseldorf.de; Wolfgang Koenig* - wolfgang.koenig@uniklinik-ulm.de; Thomas Illig - illig@helmholtz-muenchen.de

* Corresponding author
\end{abstract}

Published: 25 February 2008

BMC Medical Genetics 2008, 9:9 doi:10.1 186/147|-2350-9-9
Received: 12 September 2007

Accepted: 25 February 2008

This article is available from: http://www.biomedcentral.com/l47I-2350/9/9

(c) $2008 \mathrm{Kolz}$ et al; licensee BioMed Central Ltd.

This is an Open Access article distributed under the terms of the Creative Commons Attribution License (http://creativecommons.org/licenses/by/2.0), which permits unrestricted use, distribution, and reproduction in any medium, provided the original work is properly cited.

\begin{abstract}
Background: Toll-like receptor 4 (TLR4), the signaling receptor for lipopolysaccharides, is an important member of the innate immunity system. Since several studies have suggested that type 2 diabetes might be associated with changes in the innate immune response, we sought to investigate the association between genetic variants in the TLR4 gene and incident type 2 diabetes.

Methods: A case-cohort study was conducted in initially healthy, middle-aged subjects from the MONICA/KORA Augsburg studies including 498 individuals with incident type 2 diabetes and I,569 noncases. Seven SNPs were systematically selected in the TLR4 gene and haplotypes were reconstructed.

Results: The effect of TLR4 SNPs on incident type 2 diabetes was modified by the ratio of total cholesterol to high-density lipoprotein cholesterol (TC/HDL-C). In men, four out of seven TLR4 variants showed significant interaction with TC/HDL-C after correction for multiple testing $(p<0.01)$. The influence of the minor alleles of those variants on the incidence of type 2 diabetes was observed particularly for male patients with high values of TC/HDL-C. Consistent with these findings, haplotype-based analyses also revealed that the effect of two haplotypes on incident type 2 diabetes was modified by TC/HDL-C in men $\left(p<10^{-3}\right)$. However, none of the investigated variants or haplotypes was associated with type 2 diabetes in main effect models without assessment of effect modifications.

Conclusion: We conclude that minor alleles of several TLR4 variants, although not directly associated with type 2 diabetes might increase the risk for type 2 diabetes in subjects with high TC/HDL-C. Additionally, our results confirm previous studies reporting sex-related dissimilarities in the development of type 2 diabetes.
\end{abstract}




\section{Background}

Subclinical, low-grade systemic inflammation has been implicated in the pathogenesis and prediction of type 2 diabetes. Several studies have shown that elevated levels of inflammatory and endothelial cell markers predict diabetes [1]. Both animal models and studies in humans have suggested that type 2 diabetes might be associated with changes in the innate immune response [1-3].

Toll-like receptors are members of the interleukin 1 receptor family, an evolutionary conserved signalling system against invading pathogens [4]. Due to their ability to recognize microbial components, mammalian toll-like receptors are among the most important components of the innate immunity pathway [5]. The first described and best-known member of this family is TLR4, identified as the signaling receptor for lipopolysaccharides [6]. TLR4 also interacts with endogenous ligands such as heat shock proteins [7], fibronectin, fibrinogen [8], minimally modified and oxidized low-density lipoprotein (LDL) $[9,10]$ and free fatty acids [11], which are elevated in diabetes [12-14]. TLR4 ligation activates several intracellular signalling pathways, with TLR4/nuclear factor $\kappa B$ pathway being the most important one [15], leading to the synthesis and release of inflammatory cytokines and other costimulatory molecules that provide a link to adaptive immunity [16].

To date several single nucleotide polymorphisms (SNPs) have been identified in the TLR4 gene. Two of them, the congregated Asp299Gly and the Thr399Ile have been intensively studied and the rare allele 299Gly has been shown to cause hyporesponsiveness to lipopolysaccharides [17] and was reported to be associated with reduced incidence of carotid plaques and slowing progression of carotid atherosclerosis, as measured by carotid artery intima-media thickness [18].

Human genetic association studies of the TLR4 gene include only few that have assessed the relationship between genotype and type 2 diabetes and its complications and most of these studies have been restricted to those two polymorphisms, without consideration of the patterns of variation across the locus as a whole. Since a chronic low-grade inflammation seen in type 2 diabetes and in atherosclerosis may be related to common genetic predisposition and environmental risk factors, modulation of the systemic immune balance through gene polymorphisms might play a crucial role. Moreover, to our knowledge, there are no published prospective data evaluating the association between TLR4 variants and the development of type 2 diabetes. Therefore, we sought to systematically investigate the gender-specific association between genetic variants in the gene coding for the TLR4 receptor and incident type 2 diabetes in a prospective pop- ulation-based case-cohort study. In addition, given that TLR4 has been reported to bind LDL $[9,10]$, we wanted to analyze whether cholesterol levels have an effect on this association.

\section{Methods \\ Study design}

We designed a prospective case-cohort study within the population-based Monitoring of Trends and Determinants in Cardiovascular Disease (MONICA)/Cooperative Health Research in the Augsburg Region (KORA) Augsburg cohort study (1984-2002) [19]. As part of the international WHO MONICA project, three independent cross-sectional population-based studies (surveys) covering the city of Augsburg (Germany) and two adjacent counties were conducted in 1984/85 (S1), 1989/90 (S2) and 1994/95 (S3) to estimate the prevalence and distribution of cardiovascular risk factors among individuals aged 25 to 64 (S1) or 25 to 74 years (S2, S3). The study complies with the declaration of Helsinki. Approval was obtained by local ethic committees and informed consent was given from all patients. The total number of participants was 13,427 (6,725 men and 6,702 women). All subjects were prospectively followed within the framework of the MONICA/KORA studies [20]. The present study was restricted to subjects aged 35 to 74 years at baseline, since the incidence of type 2 diabetes is low in younger subjects. Altogether 10,718 persons (5,382 men and 5,336 women) of this age range participated in at least one of the three baseline surveys. After exclusion of 1,187 subjects with missing blood samples and 1,595 participants with prevalent type 2 diabetes, incident diabetes other than type 2 diabetes (e.g. type 1 or secondary diabetes), with self-reported, but not validated incident type 2 diabetes, without follow-up information or with a follow-up time of $<1$ year, the source population for the present study comprised 7,936 subjects (3,894 men and 4,042 women).

From the source population, a random sample was selected stratifying by sex and survey leading to a subcohort of 1,885 participants. After exclusion of subjects with missing DNA samples and missing values for risk factors, the final subcohort included 1,687 subjects (910 men, 777 women).

Additionally, all incident type 2 diabetes cases in the source population were selected, including subjects for whom the treating physician clearly reported the diagnosis or for whom the diagnosis was mentioned in the medical records or who were taking antidiabetic medication. The number of incident type 2 diabetes cases until December $31^{\text {st }}, 2002$ was 555 (329 men, 226 women). After exclusion of subjects with incomplete information on relevant variables, the present study including the subcohort and incident type 2 diabetes cases, was based on 2,067 
participants (307 men, 191 women with incident type 2 diabetes; 835 men, 734 women without incident type 2 diabetes). Mean follow-up time $( \pm \mathrm{SD})$ was $10.1( \pm 4.9)$ years. The final stratum-specific sample sizes of this subcohort were used together with the stratum-specific sizes of the source population to compute sampling fractions, and the inverse of the sampling fractions yielded surveyand sex-specific sampling weights.

All cross-sectional analyses concerning SNP frequencies and tests for departures from Hardy-Weinberg-equilibrium were performed in a random sample of the whole study population with available DNA (i.e. without prior to exclusion of subjects without follow-up information, prevalent diabetes, etc.). This sample included 1,968 subjects (1,069 men, 899 women).

\section{Selection and genotyping of polymorphisms}

For the SNP selection, the National Center for Biotechnology Information SNP database dbSNP Build 124 was used [21]. SNPs were chosen on the basis of density, frequency and occurrence in or near functional regions like exons and hypothetical promoter regions and hypothetical transcription factor-binding sites. In addition, all up to then known haplotype tagging SNPs were taken into account.

PCR primers were designed by Sequenom's MassArrayAssayDesign program. Genotyping analyses were carried out by means of matrix-assisted laser desorption ionizationtime of flight analysis of allele dependent primer extension products as described elsewhere [22]. Genotyping calls were made in real time with MassArray RT software (Sequenom, San Diego, USA). Negative controls were included in all assays. To control for reproducibility of genotyping data, $12.5 \%$ of randomly selected samples were genotyped in duplicate. The discordance rate was $0.3 \%$. Each SNP was tested for departures from HardyWeinberg-equilibrium by means of a chi-square test or Fisher's exact test depending on allele frequency.

\section{Assessment of demographic, lifestyle and clinical characteristics}

Standardized interviews were conducted by trained medical staff (mainly nurses) to assess information concerning sociodemographic variables, smoking habits, leisure time physical activity level and alcohol consumption. In addition, participants underwent a standardized medical examination and a nonfasting venous blood sample was obtained. Detailed information on all survey methods has been described elsewhere in detail [23]. TC and HDL-C were measured by enzymatic methods (CHOD-PAP, Boehringer Mannheim, Germany). HDL-C was precipitated with phosphotungstic acid and magnesium ions.

\section{Statistical analysis}

Means or proportions for baseline demographic and clinical characteristics were computed using the SAS procedures SURVEYREG or SURVEYFREQ which estimate standard errors appropriate to the sampling scheme. Tests of differences between subjects with and without incident type 2 diabetes were based on these procedures. In case of non-normality, tests were carried out with log-transformed variables and results were presented as geometric means with antilogs of standard errors of the log means.

Cox proportional hazards regression analysis was used to assess the association between polymorphisms within the TLR4 gene and incident type 2 diabetes. Due to the casecohort design, standard errors were corrected using a "sampling weight" approach developed by Barlow (1994) [24]. Since sex-related differences seem to play a role in the development of diabetes [23,25], all analyses were done separately for men and women and carried out for each TLR4 SNP with a multivariate-adjusted model including age, body mass index (BMI), systolic blood pressure (SBP), TC/HDL-C, as well as the categorical variables survey, smoking status (never smoker, former smoker, current smoker), alcohol consumption (men 0, $0.1-39.9, \geq 40 \mathrm{~g} / \mathrm{d}$; women $0,0.1-19.9, \geq 20 \mathrm{~g} / \mathrm{d}$ ) and physical activity (inactive vs. active, i.e. regular physical activity of $\geq 1$ hour/week in both summer and winter). This model was respectively notated as "main effect model". To assess whether the impact of TLR4 variants on incident type 2 diabetes was modified by cholesterol levels, interaction terms of TLR4 variants and TC/HDL-C were additionally included to the main effect model ("interaction effect model"). Hazard ratios are presented with their 95\% confidence intervals. P-values are based on robust variance estimates using the Barlow approach.

As measures for pairwise linkage disequilibrium (LD) between each pair of SNP loci, Lewontin's disequilibrium coefficient $\mathrm{D}^{\prime}$ and the squared correlation coefficient were calculated. Haplotype reconstruction was performed within blocks of high D' using the expectation-maximization algorithm haplo.em [26]. To avoid large reconstruction errors resulting from missing data, haplotype estimation is based only on subjects with complete genotype information. Due to the study design, haplotype estimation for analysis of incident type 2 diabetes had to be performed separately for cases and non-cases. For association analysis within the population-based subcohort, no distinction had to be made for haplotype estimation. Haplotypes with frequencies $<1 \%$ were collected into a separate group of rare haplotypes ("haplo rare"). The most frequent haplotype was used as the reference category. The effect of haplotypes on incident type 2 diabetes was assessed in an analogous way as for single SNPs. Due to the continuous coding of the expected number of hap- 
lotypes, an additive effect had to be assumed in haplotype association analysis.

The global significance level of $5 \%$ was corrected for the number of independent tests following the Bonferroni procedure. The number of independent tests was calculated as the number of effective loci obtained through spectral decomposition of the correlation matrix of all SNPs analyzed [27]. Therefore, the significance level for single tests was reduced to $\alpha=0.01$, corresponding to an overall significance level of $\alpha=0.05$. All statistical analyses were performed using the statistical package SAS Version 9.1 (SAS Institute, Cary, NC) and the statistical analysis software package R, Version 2.4.1 [28].

\section{Results}

Basic description of study population

The baseline demographic, clinical and lifestyle characteristics of the study participants are shown in Table 1. Subjects who developed type 2 diabetes during the follow-up period (cases) were older, showed a higher BMI, were more likely to be current or former smokers and were less active than subjects without onset of type 2 diabetes (non- cases). Furthermore, cases more frequently reported a history of myocardial infarction and hypertension, whereas no significant differences were observed for alcohol consumption between the two groups. As expected, TC and TC/HDL-C were considerably higher and HDL-C was considerably lower in cases compared to non-cases. Furthermore, cases had higher systolic and diastolic blood pressure compared to non-cases.

\section{Association of TLR4 variants and haplotypes with type 2 diabetes in main effect models}

Seven SNPs were genotyped in the TLR4 gene with a mean genotyping success rate of $98.7 \%$. The assay for rs 4986790 (Asp299Gly) failed, but it was tagged by rs4986791 (Thr399Ile). The characteristics of all SNPs are summarized in Table 2 . The genotype frequencies of the analyzed SNPs were consistent with Hardy-Weinberg-equilibrium criteria. For three SNPs (rs4986791, rs7873784 and rs1927906) the homozygotes for the minor allele were pooled with the heterozygotes in the association analysis in order to avoid conclusions from low numbers, especially as results where analyzed stratified by gender. None of the SNPs in the TLR4 gene was significantly associated

Table I: Baseline demographic, lifestyle and clinical characteristics of the study participants during follow-up $(n=2,067)$. Data are weighted percentages for categorical variables and weighted means (standard errors) for normally distributed continuous variables.

\begin{tabular}{|c|c|c|c|}
\hline & Cases $(N=498)$ & Non-cases $(N=1569)$ & $p$-value* \\
\hline \multicolumn{4}{|l|}{ Demographic } \\
\hline Sex $=$ male $[\%]$ & 61.7 & 53.2 & $<0.001$ \\
\hline Age [yrs] & $56.0(0.4)$ & $51.6(0.3)$ & $<0.001$ \\
\hline \multicolumn{4}{|l|}{ Clinical } \\
\hline Body Mass Index $\left[\mathrm{kg} / \mathrm{m}^{2}\right]$ & $30.0(0.2)$ & $26.7(0.1)$ & $<0.001$ \\
\hline Systolic Blood Pressure [mmHg] & $142.2(0.8)$ & $132.7(0.5)$ & $<0.001$ \\
\hline Diastolic Blood Pressure [mmHg] & $85.3(0.5)$ & $81.5(0.3)$ & $<0.001$ \\
\hline History of actual hypertension [\%] & 66.5 & 39.8 & $<0.001$ \\
\hline History of myocardial infarction [\%] & 5.0 & 1.9 & 0.003 \\
\hline Total cholesterol $[\mathrm{mg} / \mathrm{dl}]$ & $247.4(2.0)$ & $235.9(1.1)$ & $<0.001$ \\
\hline HDL cholesterol [mg/dl] & $47.9(0.6)$ & $57.6(0.4)$ & $<0.001$ \\
\hline Ratio TC/HDL-C & $5.6(0.1)$ & $4.5(0.0)$ & $<0.001$ \\
\hline \multicolumn{4}{|l|}{ Lifestyle } \\
\hline Smoking status [\%] & & & 0.002 \\
\hline Current smoker & 26.9 & 24.2 & \\
\hline Former smoker & 33.3 & 27.2 & \\
\hline Never smoker & 39.8 & 48.6 & \\
\hline Frequency of exercise [\%] & & & $<0.001$ \\
\hline Inactive & 69.1 & 58.3 & \\
\hline Active & 30.9 & 41.7 & \\
\hline Alcohol consumption ${ }^{\dagger}[\%]$ & & & 0.112 \\
\hline $0 \mathrm{~g} / \mathrm{d}$ & 32.1 & 28.5 & \\
\hline $0-39.9 / 0-19.9 \mathrm{~g} / \mathrm{d}$ & 39.4 & 44.6 & \\
\hline$\geq 40 / 20 \mathrm{~g} / \mathrm{d}$ & 28.5 & 26.9 & \\
\hline Survey $\ddagger$ & & & $<0.001$ \\
\hline SI [\%] & 36.5 & 28.9 & \\
\hline S2 [\%] & 39.4 & 36.1 & \\
\hline S3 [\%] & 24.1 & 35.0 & \\
\hline
\end{tabular}

* $\mathrm{t}$-test for continuous variables and chi-square-test for categorical variables; † Men: $0 \mathrm{~g} / \mathrm{d}, 0-39.9 \mathrm{~g} / \mathrm{d}, \geq 40 \mathrm{~g} / \mathrm{d} ;$ Women: $0 \mathrm{~g} / \mathrm{d}, 0-19.9 \mathrm{~g} / \mathrm{d}, \geq 20 \mathrm{~g} / \mathrm{d} ;$; Independent cross-sectional study 
Table 2: Description of TLR4 variants genotyped $(n=I, 968)$.

\begin{tabular}{|c|c|c|c|c|c|c|}
\hline \multirow[t]{2}{*}{ SNP number } & \multirow[t]{2}{*}{ dbSNP identifier } & \multirow{2}{*}{$\begin{array}{c}\text { Exchange } \\
(1>2)\end{array}$} & \multicolumn{3}{|c|}{ Genotype frequencies ${ }^{a}$} & \multirow[t]{2}{*}{ Gene location } \\
\hline & & & II & 12 & 22 & \\
\hline 1 & rs 2770150 & $\mathrm{~T}>\mathrm{C}$ & 52.6 & 40.1 & 7.3 & 5'Upstream \\
\hline 2 & rs6478317 & $A>G$ & 46.5 & 42.7 & 10.8 & 5'Upstream \\
\hline 3 & rs19279|I & $\mathrm{C}>\mathrm{T}$ & 57.6 & 35.7 & 6.7 & Intronic \\
\hline 4 & rs2149356 & $C>A$ & 47.7 & 42.2 & 10.1 & Intronic, TFBS \\
\hline 5 & rs498679l & $\mathrm{C}>\mathrm{T}$ & 88.1 & 11.6 & 0.3 & Ile399Thr, HMCS \\
\hline 6 & rs7873784 & $G>C$ & 74.2 & 23.4 & 2.4 & 3'Untranslated region \\
\hline 7 & rs1927906 & $A>G$ & 81.3 & 18 & 0.8 & 3'Flanking \\
\hline
\end{tabular}

aweighted due to the sampling schene; TFBS: Transcription factor binding site; HMCS: human-mouse conserved segments

with incident type 2 diabetes in multivariate-adjusted models including age, BMI, SBP, TC/HDL-C, survey, smoking status, alcohol consumption and physical activity.

The LD structure across the TLR4 loci is shown in Figure 1. The strength of LD was reflected by restricted haplotype diversity. Three major haplotypes were observed with frequencies ranging from $13 \%$ to $41 \%$ (Table 3 ). The haplotype $\mathrm{H} 1$ carrying the major allele at all loci was used as the reference category. Similar to the analysis of the single SNPs, none of the haplotypes was associated with increased risk of incident type 2 diabetes.

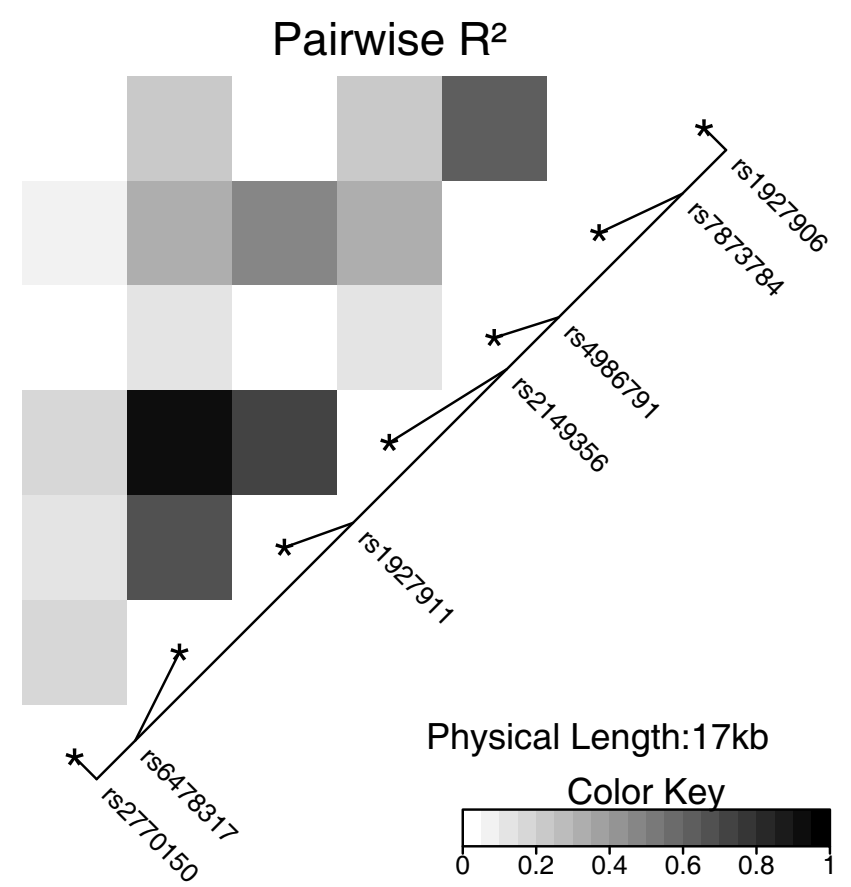

\section{Association of TLR4 variants and haplotypes with type 2 diabetes in interaction effect models}

The effect of TLR4 SNPs on incident type 2 diabetes was modified by TC/HDL-C in men. Five out of seven TLR4 variants showed significant interaction with TC/HDL-C with $\mathrm{p}$ values $<0.018$ (test with two degrees of freedom). Four of them remained significant after correction for multiple testing $(\mathrm{p}<0.01)$. In women, no significant effect modification by TC/HDL-C was observed. Hazard ratios of incident type 2 diabetes for each SNP related to the respective TC/HDL-C concentration are shown in Figures 2, 3, 4, 5, 6, 7, 8 for men and Figures 9, 10, 11, 12, 13, 14,15 for women including the p-values for main and interaction effects above each figure.

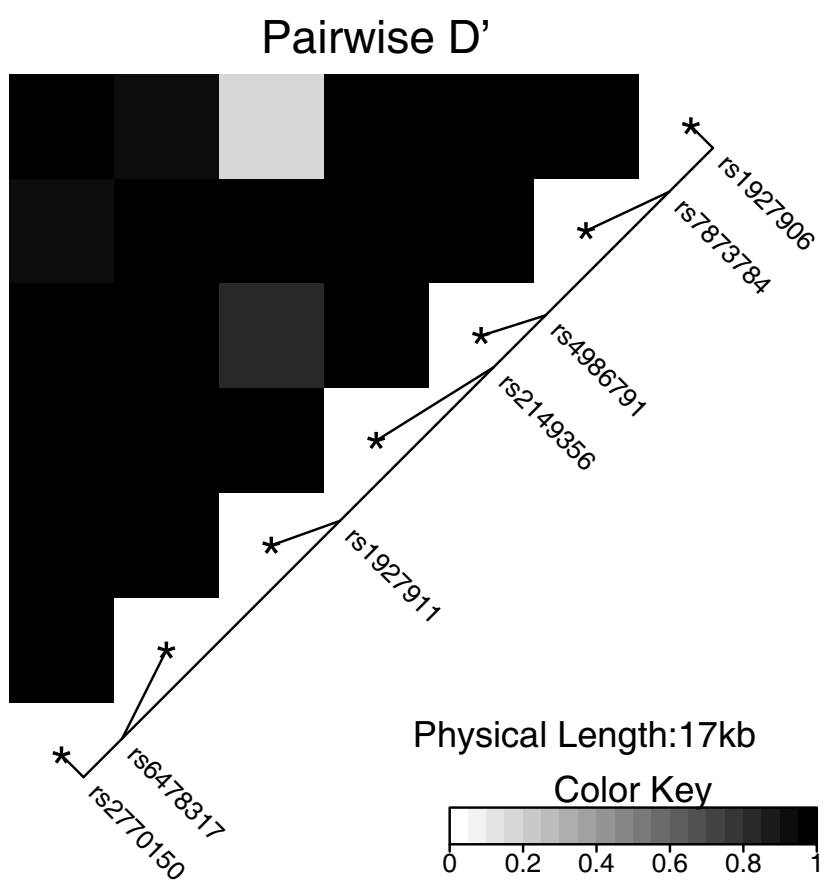

Figure I

Structure of the TLR4 gene and pairwise LD D' und $r^{2}$ plots. 
Table 3: Description of TLR4 haplotypes in the randomly drawn subcohort $(n=1,968)$.

\begin{tabular}{ccccccccccc}
\hline Haplotype & \multicolumn{4}{c}{ SNP number } & \multicolumn{4}{c}{ Frequency [\%] } \\
\hline & I & $\mathbf{2}$ & $\mathbf{3}$ & $\mathbf{4}$ & $\mathbf{5}$ & $\mathbf{6}$ & $\mathbf{7}$ & Men & Women \\
\hline HI & T & A & C & C & C & G & A & 0.41 & 0.39 \\
H2 & C & A & C & C & C & G & A & 0.27 & 0.28 \\
H3 & T & G & T & A & C & C & A & 0.13 & 0.15 \\
H4 & T & G & T & A & C & G & A & 0.07 & 0.07 \\
H5 & T & G & C & A & T & G & G & 0.06 & 0.06 \\
H6 & T & G & T & A & C & G & G & 0.04 & 0.03 \\
H7 & T & G & C & C & C & G & A & 0.01 & 0.01 \\
Rare & & & & & & & & 0.01 & 0.01 \\
\hline
\end{tabular}

For rs6478317 (Figure 3), rs1927911 (Figure 4) and rs2149356 (Figure 5), the hazard ratio of the heterozygote genotype compared to the homozygote genotype of the common allele increased with rising TC/HDL-C from below $1(\mathrm{TC} / \mathrm{HDL}-\mathrm{C}<5)$ to 1.5 or more $(\mathrm{TC} / \mathrm{HDL}-\mathrm{C}>8)$. Similar results were observed for rs4986791 (Figure 6) and rs1927906 (Figure 8) where heterozygotes and homozygotes for the minor allele were combined. We conducted several sensitivity analyses to ensure the observed associations. Further adjustment for lipid lowering drug intake or exclusion of participants with lipid low

rs2770150

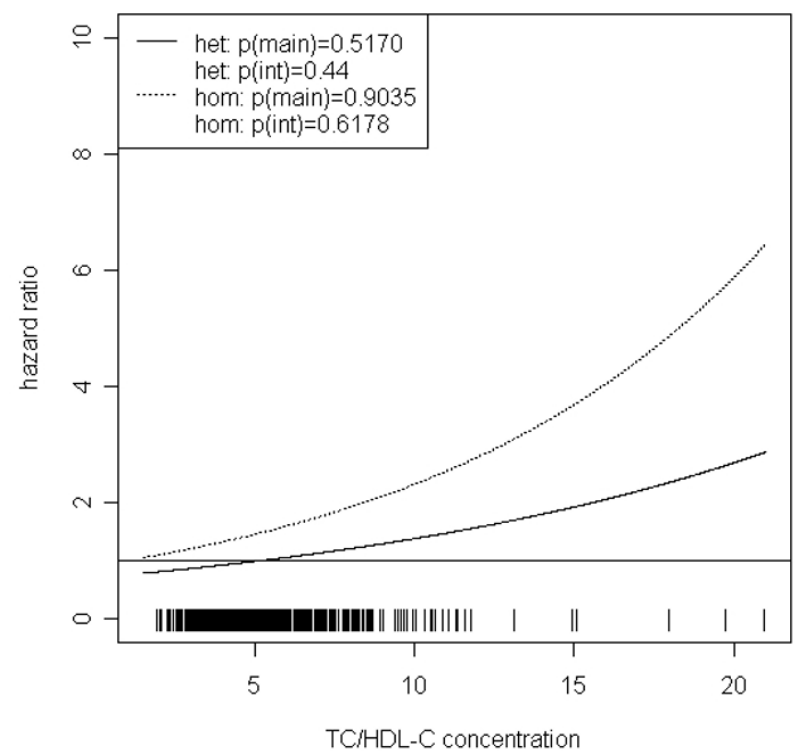

Figure 2

Hazard ratios of incident type 2 diabetes related to the respective TC/HDL-C concentration in men for rs 2770 I 50. Dashed lines represent subjects who are homozygote for the minor allele, while continuous lines show heterozygotes. Small bars at the $x$-axis indicate TC/HDL$\mathrm{C}$ concentrations of patients with at least one copy of the minor allele. rs6478317

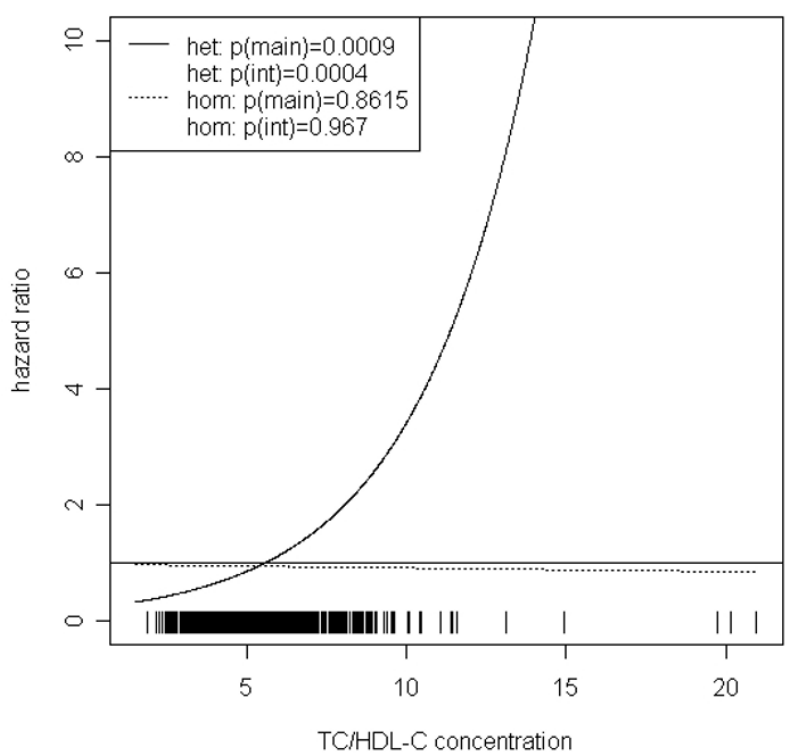

Figure 3

Hazard ratios of incident type 2 diabetes related to the respective TC/HDL-C concentration in men for rs64783 I7. Dashed lines represent subjects who are homozygote for the minor allele, while continuous lines show heterozygotes. Small bars at the $x$-axis indicate TC/HDL$\mathrm{C}$ concentrations of patients with at least one copy of the minor allele.

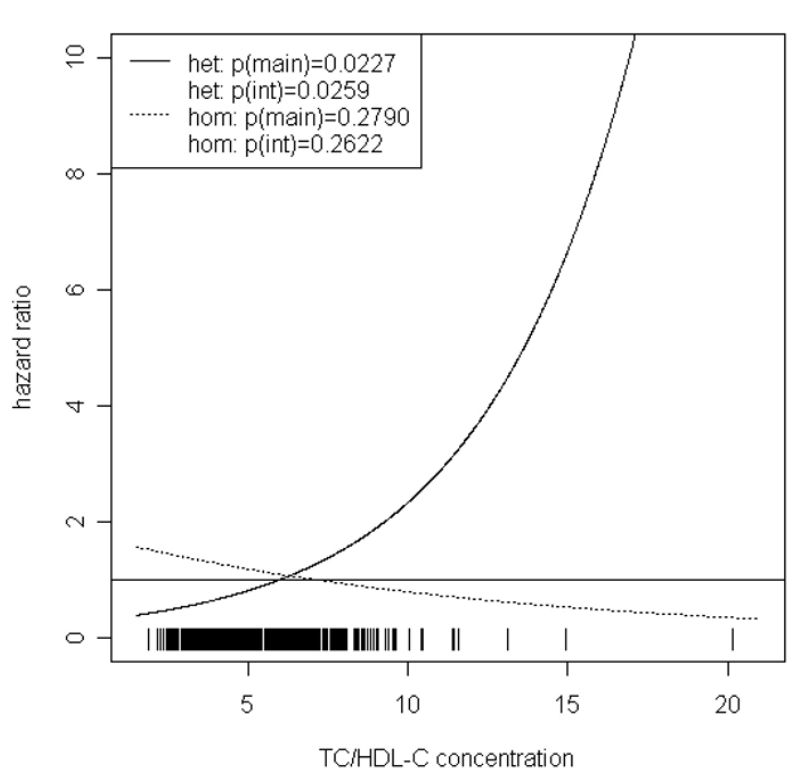

Figure 4

Hazard ratios of incident type 2 diabetes related to the respective TC/HDL-C concentration in men for rs 19279 II. Dashed lines represent subjects who are homozygote for the minor allele, while continuous lines show heterozygotes. Small bars at the $x$-axis indicate TC/HDL$\mathrm{C}$ concentrations of patients with at least one copy of the minor allele. 
rs2149356

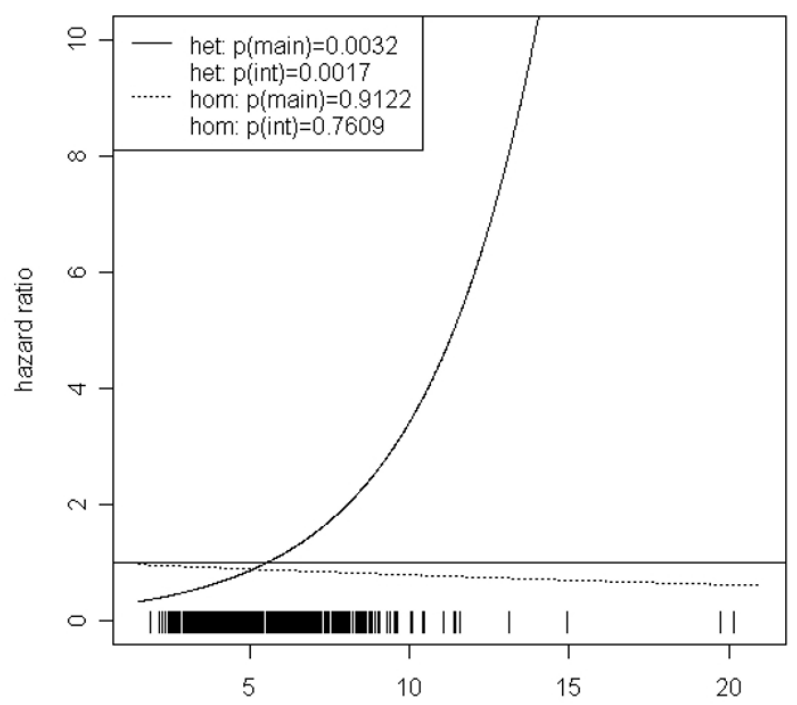

TC/HDL-C concentration

\section{Figure 5}

Hazard ratios of incident type 2 diabetes related to the respective TC/HDL-C concentration in men for rs2 149356. Dashed lines represent subjects who are homozygote for the minor allele, while continuous lines show heterozygotes. Small bars at the $x$-axis indicate TC/HDL$\mathrm{C}$ concentrations of patients with at least one copy of the minor allele.

rs4986791

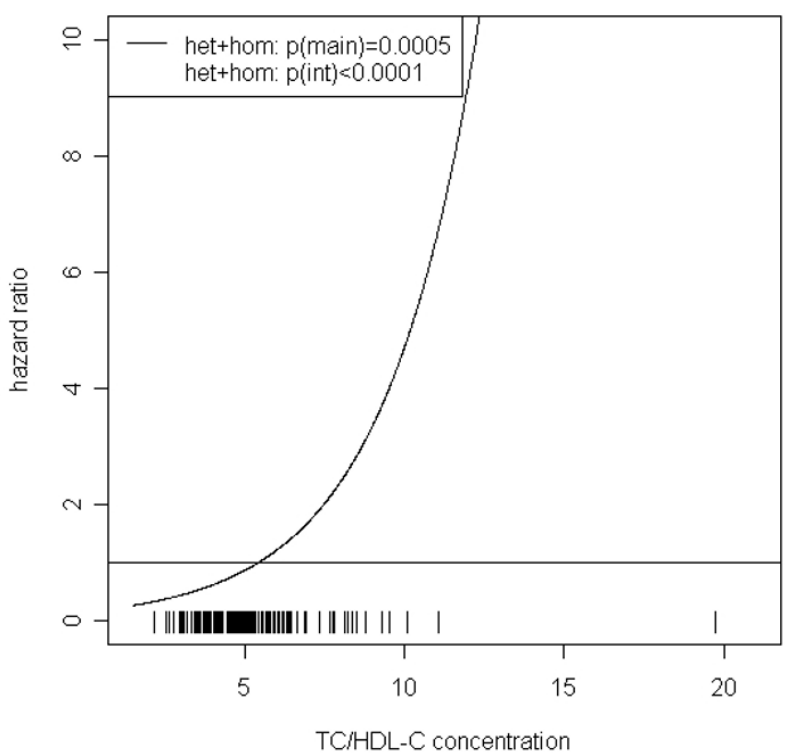

Figure 6

Hazard ratios of incident type 2 diabetes related to the respective TC/HDL-C concentration in men for rs498679I. Continuous lines represent subjects who are heterozygote or homozygote for the minor allele. Small bars at the $\mathrm{x}$-axis indicate TC/HDL-C concentrations of patients with at least one copy of the minor allele. rs7873784

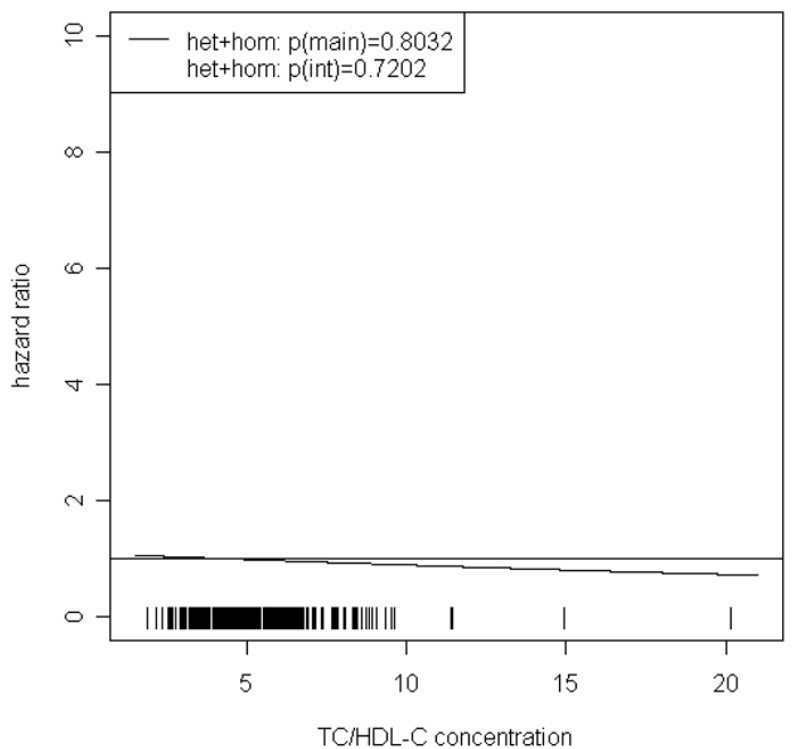

Figure 7

Hazard ratios of incident type 2 diabetes related to the respective TC/HDL-C concentration in men for rs7873784. Continuous lines represent subjects who are heterozygote or homozygote for the minor allele. Small bars at the $x$-axis indicate TC/HDL-C concentrations of patients with at least one copy of the minor allele.

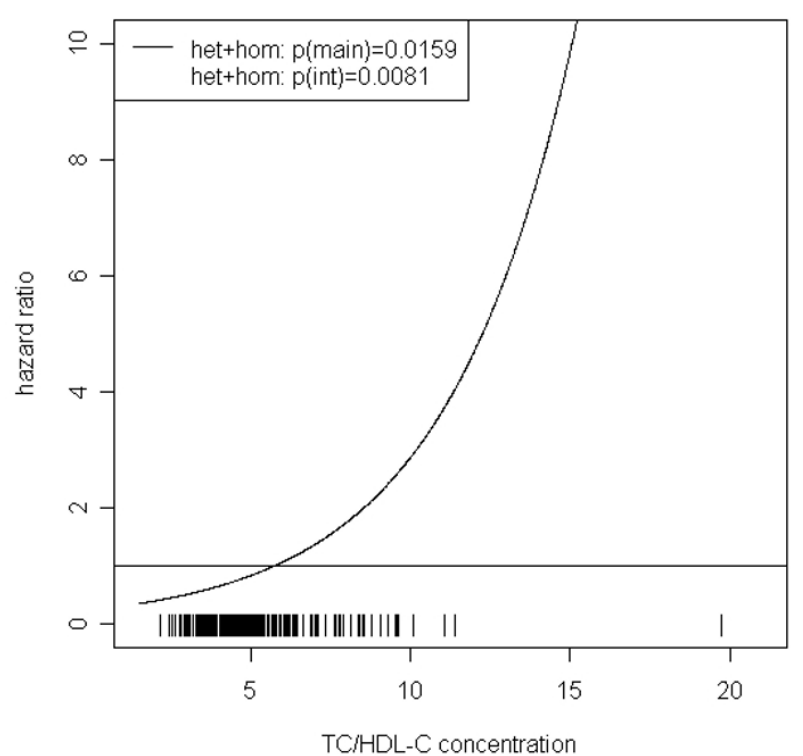

Figure 8

Hazard ratios of incident type 2 diabetes related to the respective TC/HDL-C concentration in men for rs 1927906 . Continuous lines represent subjects who are heterozygote or homozygote for the minor allele. Small bars at the $x$-axis indicate TC/HDL-C concentrations of patients with at least one copy of the minor allele. 
rs2770150

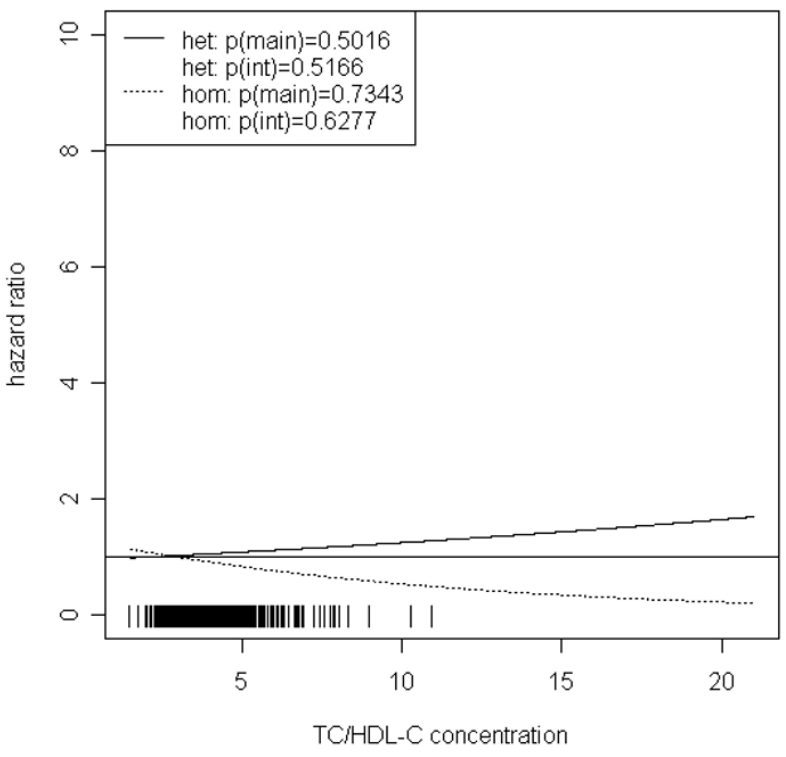

\section{Figure 9}

Hazard ratios of incident type 2 diabetes related to the respective TC/HDL-C concentration in women for rs2770 I50. Dashed lines represent subjects who are homozygote for the minor allele, while continuous lines show heterozygotes. Small bars at the $\mathrm{x}$-axis indicate TC HDL-C concentrations of patients with at least one copy of the minor allele.

\section{rs6478317}

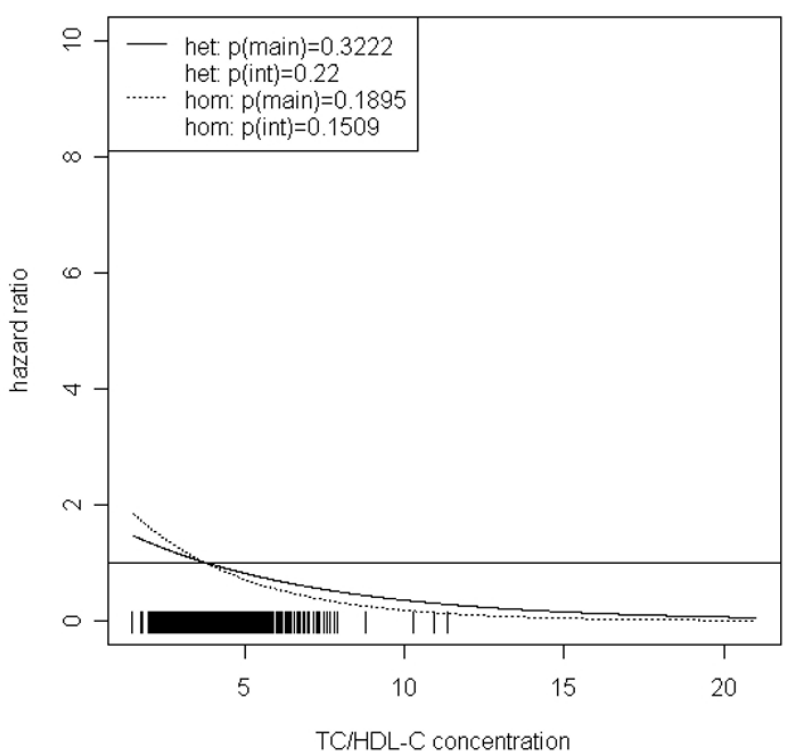

Figure 10

Hazard ratios of incident type 2 diabetes related to the respective TC/HDL-C concentration in women for $r \mathbf{6 4 7 8 3 1 7}$. Dashed lines represent subjects who are homozygote for the minor allele, while continuous lines show heterozygotes. Small bars at the $x$-axis indicate TC/ HDL-C concentrations of patients with at least one copy of the minor allele. rs1927911

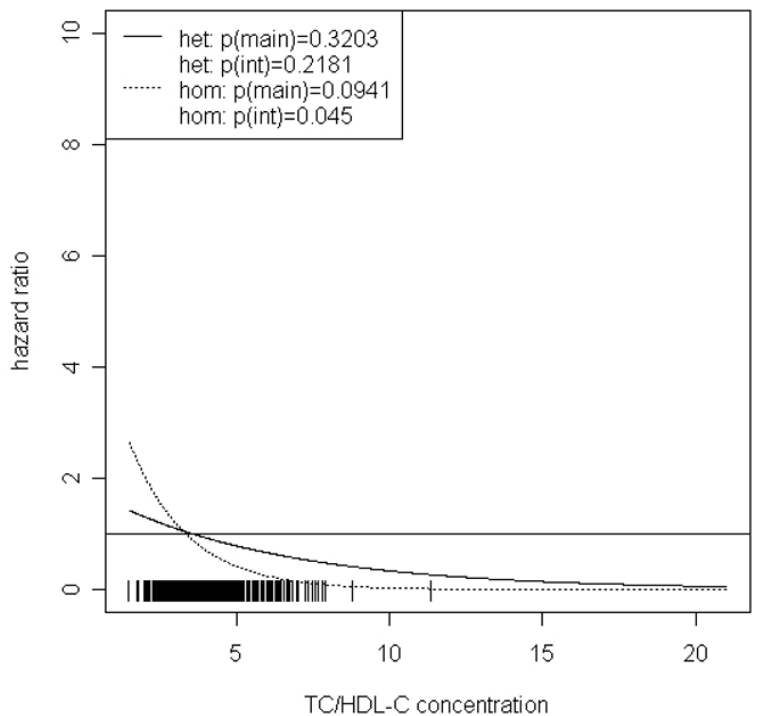

Figure I I

Hazard ratios of incident type 2 diabetes related to the respective TC/HDL-C concentration in women for rs 19279 II. Dashed lines represent subjects who are homozygote for the minor allele, while continuous lines show heterozygotes. Small bars at the $x$-axis indicate TCl HDL-C concentrations of patients with at least one copy of the minor allele.

rs2149356

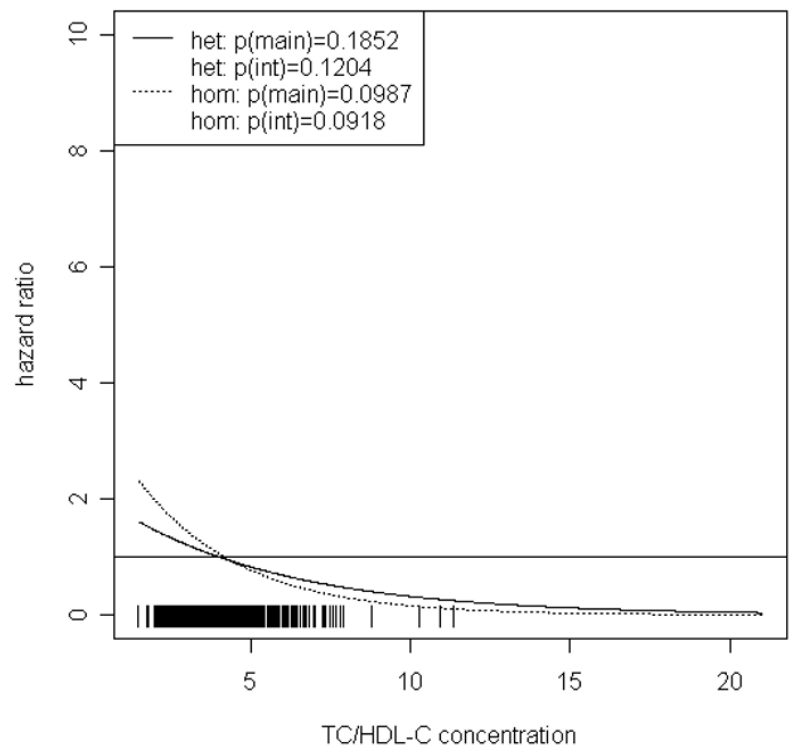

\section{Figure 12}

Hazard ratios of incident type 2 diabetes related to the respective TC/HDL-C concentration in women for rs2 149356. Dashed lines represent subjects who are homozygote for the minor allele, while continuous lines show heterozygotes. Small bars at the $\mathrm{x}$-axis indicate TC/ $\mathrm{HDL}-\mathrm{C}$ concentrations of patients with at least one copy of the minor allele. 
rs4986791

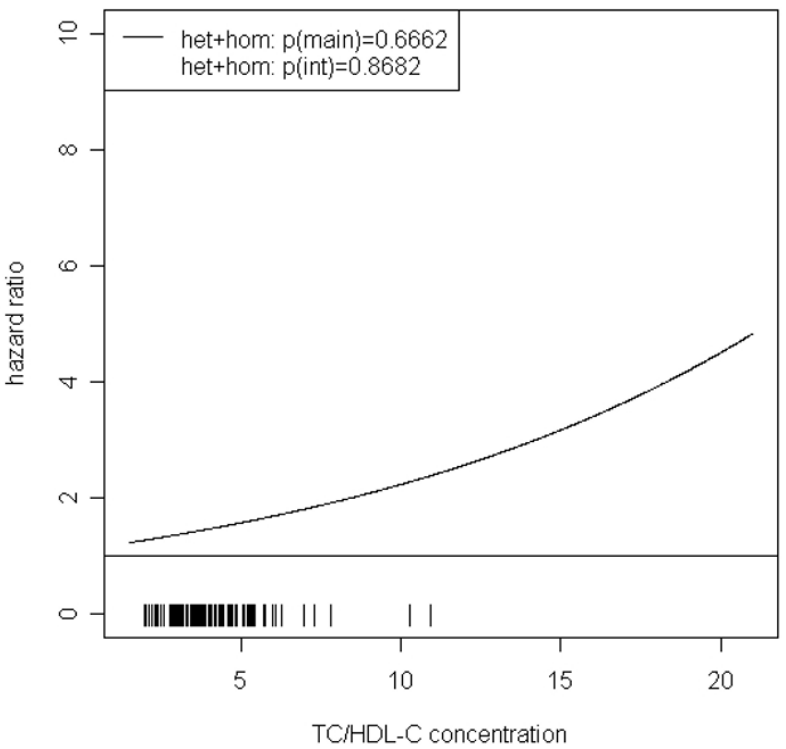

Figure 13

Hazard ratios of incident type 2 diabetes related to the respective TC/HDL-C concentration in women for rs498679 I. Continuous lines represent subjects who are heterozygote or homozygote for the minor allele. Small bars at the $\mathrm{x}$-axis indicate TC/HDL-C concentrations of patients with at least one copy of the minor allele.

\section{rs7873784}

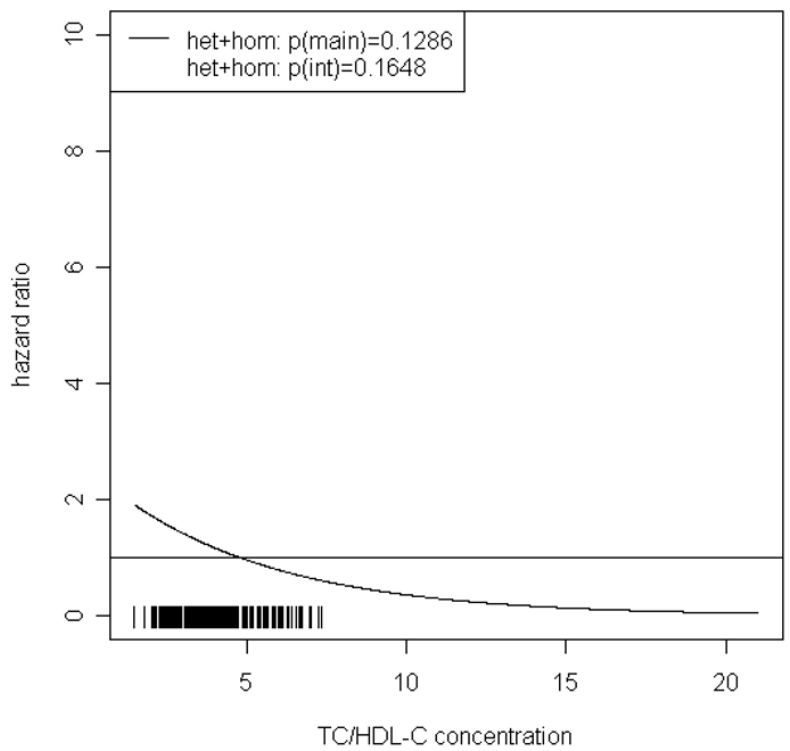

Figure 14

Hazard ratios of incident type 2 diabetes related to the respective TC/HDL-C concentration in women for rs7873784. Continuous lines represent subjects who are heterozygote or homozygote for the minor allele. Small bars at the $\mathrm{x}$-axis indicate TC/HDL-C concentrations of patients with at least one copy of the minor allele.

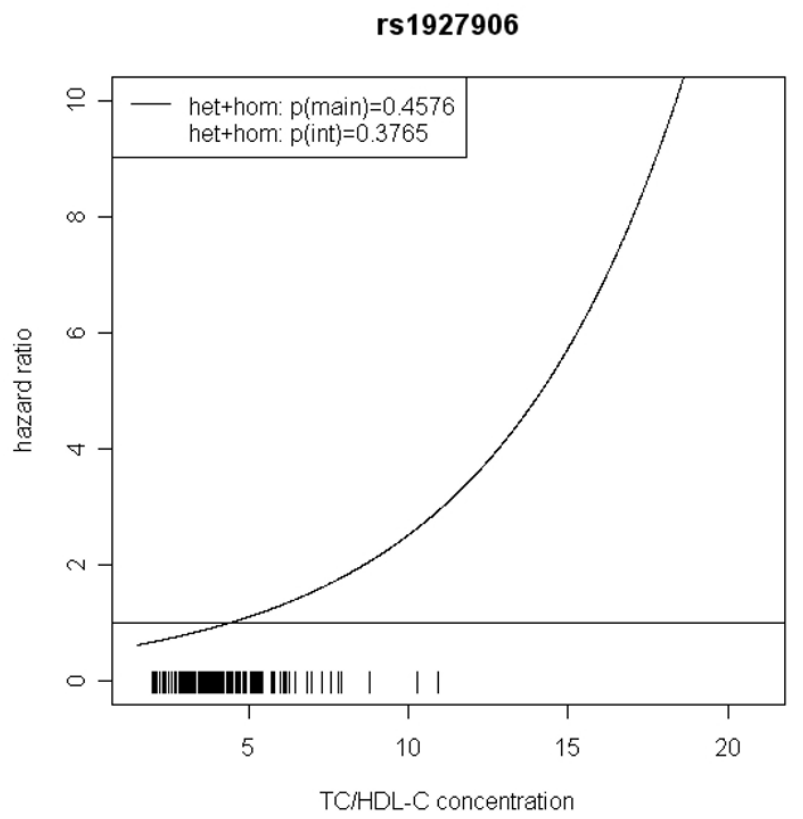

Figure 15

Hazard ratios of incident type 2 diabetes related to the respective TC/HDL-C concentration in women for rs 1927906 . Continuous lines represent subjects who are heterozygote or homozygote for the minor allele. Small bars at the $x$-axis indicate TC/HDL-C concentrations of patients with at least one copy of the minor allele.

ering drug intake revealed very similar results. When analysing interactions excluding subjects with extreme TC/ HDL-C values (below or above one percent of the distribution), the effect modifications remained but did not reach the level of statistical significance. The findings of the single SNP analysis were supported by the haplotype analysis shown in Table 4. In men, the effect of TLR4 haplotypes $\mathrm{H} 5$ and $\mathrm{H} 7$ on incident type 2 diabetes was modified by TC/HDL-C. Additionally, borderline significance was obtained for $\mathrm{H} 4$ in men and for $\mathrm{H} 2, \mathrm{H} 3$ and $\mathrm{H} 4$ in women. However, none of the TLR4 SNPs or haplotypes was associated with TC/HDL-C concentrations in the randomly drawn subcohort neither in men nor in women.

In order to investigate the role of sex-specific differences and to verify that our findings are not artefacts resulting from stratified analysis, we also estimated models including three-way interaction terms between sex, TC/HDL-C and the genetic variants. These additional analyses gave evidence not only for presence of sex-specific differences of the influence of TC/HDL-C but also modification of genetic effects by sex, TC/HDL-C as well as sex-specific TC/ HDL-C. For detailed results of the three-way interaction haplotype model, please see Additional file 1. 
Table 4: Results of haplotype association analysis for type 2 diabetes in interaction effect models $(n=I, 968)$.

\begin{tabular}{|c|c|c|c|c|}
\hline & \multicolumn{2}{|c|}{ Men } & \multicolumn{2}{|c|}{ Women } \\
\hline & HR $[95 \% \mathrm{Cl}]$ & p-value & HR [95\% Cl] & p-value \\
\hline TC/HDL-C & $1.02[0.90 ; 1.15]$ & 0.74 & $1.95[1.55 ; 2.45]$ & $1.2 \times 10^{-8}$ \\
\hline $\mathrm{H} 2$ & $0.77[0.36,1.65]$ & 0.5 & $3.11[1.07 ; 9.00]$ & 0.04 \\
\hline $\mathrm{H} 3$ & $1.04[0.55 ; 1.96]$ & 0.89 & $4.4 \mid[|.37 ;| 4.2 \mid]$ & 0.01 \\
\hline $\mathrm{H} 4$ & $0.29[0.08 ; 1.02]$ & 0.05 & $4.01[0.99 ; 16.17]$ & 0.05 \\
\hline H5 & $0.1 I[0.03 ; 0.45]$ & $1.9 \times 10^{-3}$ & $1.47[0.34 ; 6.40]$ & 0.61 \\
\hline $\mathrm{H} 6$ & $0.45[0.11 ; 1.73]$ & 0.24 & $0.29[0.01 ; 6.73]$ & 0.44 \\
\hline $\mathrm{H} 7$ & $0.05[0.00 ; 0.52]$ & 0.01 & $0.41[0.02 ; 10.33]$ & 0.59 \\
\hline $\mathrm{TC} / \mathrm{HDL}-\mathrm{C} \times \mathrm{H} 2$ & I.08 [0.95; I,24] & 0.22 & $0.76[0.61 ; 0.96]$ & 0.02 \\
\hline $\mathrm{TC} / \mathrm{HDL}-\mathrm{C} \times \mathrm{H} 3$ & I.01 $[0.92 ; 1.10]$ & 0.9 & $0.70[0.54 ; 0.91]$ & 0.01 \\
\hline $\mathrm{TC} / \mathrm{HDL}-\mathrm{C} \times \mathrm{H} 4$ & $1.28[1.03 ; 1.58]$ & 0.02 & $0.68[0.5 \mathrm{I} ; 0.89]$ & 0.01 \\
\hline TC/HDL-C $\times$ H5 & 1.51 [1.23; 1.87$]$ & $1.1 \times 10^{-4}$ & $0.95[0.70 ; 1.29]$ & 0.74 \\
\hline $\mathrm{TC} / \mathrm{HDL}-\mathrm{C} \times \mathrm{H} 6$ & $1.14[0.95 ; 1.37]$ & 0.15 & $1.17[0.65 ; 2.08]$ & 0.61 \\
\hline $\mathrm{TC} / \mathrm{HDL}-\mathrm{C} \times \mathrm{H} 7$ & $1.63[1.26 ; 2.12]$ & $2.1 \times 10^{-4}$ & I.I $15[0.64 ; 2.07]$ & 0.64 \\
\hline
\end{tabular}

\section{Discussion}

To the best of our knowledge, this is the first prospective study to systematically investigate the association between genetic variants in the gene coding for the TLR4 receptor and type 2 diabetes using a case-cohort design. In men the effects of TLR4 SNPs and haplotypes on incident type 2 diabetes were modified by TC/HDL-C concentrations. However, no effect was seen in women and none of the investigated SNPs or haplotypes was associated with type 2 diabetes alone.

\section{Association of TLR4 variants and haplotypes with type 2 diabetes in main effect models}

There was no association between TLR4 SNPs or haplotypes and type 2 diabetes in our prospective populationbased case-cohort study in main effect models.

Only few epidemiological studies have investigated the association of TLR4 polymorphisms with type 2 diabetes focusing only on the two classical polymorphisms Asp299Gly and Thr399Ile. We recently reported on the lack of an association between 299Gly and 3399Ile and prevalent type 2 diabetes or parameters of the metabolic syndrome using a cross-sectional approach [29]. A study in patients undergoing coronary angiography, found 299Gly carriage to be associated with a lower prevalence of diabetes [30]. However, this study represented a caseonly study and did not distinguish between type 1 and type 2 diabetes. Additionally, carriers of the minor alleles of these two polymorphisms were associated with reduced prevalence of diabetic neuropathy in a sample of type 2 diabetes patients [31].

Evidence for a role of TLR4 in type 2 diabetes came from in-vitro studies. Levels of TLR4 have been reported to be consistently elevated in the diabetic NZL mouse model.
Furthermore, dysregulated TLR4 mRNA expression correlates with high pro-inflammatory cytokine mRNA and low IL-10 levels after lipopolysaccharide stimulation [32]. During adipocyte differentiation, mRNA levels of TLR4 are remarkably enhanced in fat tissue of obese mice. Additionally, TLR4 activation provoked insulin resistance in adipocytes, suggesting that activation of TLR4 in adipocytes might be implicated in the onset of insulin resistance in obesity and type 2 diabetes [33].

\section{Association of TLR4 polymorphisms and haplotypes with incident type 2 diabetes modified by TCIHDL-C}

In the present study, the effect of TLR4 SNPs on incident type 2 diabetes was modified by TC/HDL-C in men, but not in women. To our knowledge, this effect has not been described before. An influence of the minor alleles of four TLR4 variants on the incidence of type 2 diabetes was observed particularly for patients with high levels of TC/ HDL-C and these findings were supported by haplotype analysis. In men, two haplotypes $\mathrm{H} 5$ and $\mathrm{H} 7$ showed a significant interaction with TC/HDL-C on the risk of incident type 2 diabetes. H5, the haplotype showing the strongest effect is tagged by the rare allele of the common Thr399Ile polymorphism.

The effect of Asp299Gly and Thr399Ile on coronary artery disease was evaluated in a randomized cholesterol-lowering trial. The authors reported a significant interaction between genotype and statin treatment in reducing the risk of clinical cardiovascular events. Furthermore, like in our sample, they did not observe an effect on lipid parameters alone [34].

Several in-vitro and animal studies have focused on the possible activation of the TLR pathways by hyperlipidemia. Oxidized LDL induces upregulation of TLR4 
expression in macrophages in vitro and might therefore contribute to the TLR4-dependent inflammatory process in the arterial wall [10]. An in-vitro study revealed a mechanism by which activation of TLR4 results in a strong inhibition of cholesterol efflux from macrophages [35]. Additionally, mouse models of hyperlipidemia have suggested a role for the TLR signaling pathways in hyperlipidemia-induced atherosclerosis [36].

\section{Limitations and strengths of the present study}

We studied a large cohort of middle-aged men and women of German nationality. Therefore replication in other populations is needed before results can be generalized. Strengths of the study include a population-based prospective study design with a long follow-up and the detailed systematic selection of polymorphisms using LD information available in public databases and the reconstruction of haplotypes.

\section{Conclusion}

We conclude that minor alleles of several TLR4 variants, although not directly associated with type 2 diabetes might increase the risk for type 2 diabetes in subjects with high TC/HDL-C. Our results confirm previous studies reporting sex-related dissimilarities in the development of type 2 diabetes. However, further studies are needed to replicate these results and analyse the underlying mechanisms.

\section{Competing interests}

The author(s) declare that they have no competing interests.

\section{Authors' contributions}

MK participated in the in the molecular genetic studies and drafted the manuscript. JB performed the statistical analysis. MM participated in the statistical analysis and performed haplotype reconstruction. NK participated in the design of the study. NK carried out the molecular genetic studies. BT participated in the design of the study and helped to draft the manuscript. CM participated in the design of the study and helped to draft the manuscript. CH participated in the design of the study. WK conceived of the study, and participated in its design and coordination. TI conceived of the study, and participated in its design and coordination. All authors read and approved the final manuscript.

\section{Additional material}

\section{Additional file 1}

Results of interaction effect models including three-way interaction terms between sex, TC/HDL-C and the genetic variants. Results of haplotype and SNP association analysis for men and women combined including three-way interaction terms between sex, TC/HDL-C and the genetic variants.

Click here for file

[http://www.biomedcentral.com/content/supplementary/14712350-9-9-S1.pdf]

\section{Acknowledgements}

The MONICA/KORA Augsburg cohort study was financed by the GSF National Research Center for Environment and Health and supported by grants from the Federal Ministry of Education and Research. The present study was funded by the German Research Foundation (DFG, TH-784/2-I) and the German Federal Ministry of Education, Science, Research and Technology (National Genome Research Net-2, cardiovascular, 0I GS0423).

We thank all members of the GSF-Institute of Epidemiology, who were involved in the planning and conduct of the MONICA/KORA Augsburg studies, and the MONICA Augsburg survey team. Finally, we are indebted to all study participants.

\section{References}

I. Kolb H, Mandrup-Poulsen T: An immune origin of type 2 diabetes? Diabetologia 2005, 48: 1038-1050.

2. Duncan BB, Schmidt MI: The epidemiology of low-grade chronic systemic inflammation and type 2 diabetes. Diabetes Technol Ther 2006, 8:7-17.

3. Pickup JC, Crook MA: Is type II diabetes mellitus a disease of the innate immune system? Diabetologia 1998, 4I:124|-1248.

4. Medzhitov R, Preston-Hurlburt P, Janeway CA Jr.: A human homologue of the Drosophila Toll protein signals activation of adaptive immunity. Nature 1997, 388:394-397.

5. Barton GM, Medzhitov R: Toll-like receptor signaling pathways. Science 2003, 300:1524-1525.

6. Poltorak A, He X, Smirnova I, Liu MY, Van Huffel C, Du X, Birdwell D, Alejos E, Silva M, Galanos C, Freudenberg M, Ricciardi-Castagnoli $\mathrm{P}$, Layton B, Beutler B: Defective LPS signaling in $\mathrm{C} 3 \mathrm{H} / \mathrm{HeJ}$ and C57BL/IOSCCr mice: mutations in TIr4 gene. Science 1998, 282:2085-2088.

7. Ohashi K, Burkart V, Flohe S, Kolb H: Cutting edge: heat shock protein 60 is a putative endogenous ligand of the toll-like receptor-4 complex. J Immunol 2000, 164:558-56I.

8. Smiley ST, King JA, Hancock WW: Fibrinogen stimulates macrophage chemokine secretion through toll-like receptor 4 . J Immunol 200I, 167:2887-2894.

9. Miller YI, Viriyakosol S, Binder CJ, Feramisco JR, Kirkland TN, Witztum JL: Minimally modified LDL binds to CD I 4, induces macrophage spreading via TLR4/MD-2, and inhibits phagocytosis of apoptotic cells. J Biol Chem 2003, 278: I56I-I568.

10. $\mathrm{Xu} X \mathrm{XH}$, Shah PK, Faure E, Equils O, Thomas L, Fishbein MC, Luthringer D, Xu XP, Rajavashisth TB, Yano J, Kaul S, Arditi M: Tolllike receptor-4 is expressed by macrophages in murine and human lipid-rich atherosclerotic plaques and upregulated by oxidized LDL. Circulation 200I, 104:3103-3108.

II. Shi H, Kokoeva MV, Inouye K, Tzameli I, Yin H, Flier JS: TLR4 links innate immunity and fatty acid-induced insulin resistance. J Clin Invest 2006, I 1 6:3015-3025.

12. Carr ME: Diabetes mellitus: a hypercoagulable state. J Diabetes Complications 200I, 15:44-54.

13. Keren P, George J, Shaish A, Levkovitz H, Janakovic Z, Afek A, Goldberg I, Kopolovic J, Keren G, Harats D: Effect of hyperglycemia 
and hyperlipidemia on atherosclerosis in LDL receptor-deficient mice: establishment of a combined model and association with heat shock protein $\mathbf{6 5}$ immunity. Diabetes 2000, 49:1064-1069.

14. Streja D, Cressey P, Rabkin SW: Associations between inflammatory markers, traditional risk factors, and complications in patients with type 2 diabetes mellitus. J Diabetes Complications 2003, 17:120-127.

15. Guha M, Mackman N: LPS induction of gene expression in human monocytes. Cell Signal 200I, 13:85-94.

16. Barnes PJ, Karin M: Nuclear factor-kappaB: a pivotal transcription factor in chronic inflammatory diseases. $N$ Engl J Med 1997, 336: I066-107I.

17. Arbour NC, Lorenz E, Schutte BC, Zabner J, Kline JN, Jones M, Frees K, Watt JL, Schwartz DA: TLR4 mutations are associated with endotoxin hyporesponsiveness in humans. Nat Genet 2000, 25: $|87-19|$.

18. Kiechl S, Lorenz E, ReindI M, Wiedermann C], Oberhollenzer F, Bonora E, Willeit J, Schwartz DA: Toll-like receptor 4 polymorphisms and atherogenesis. $N$ Engl J Med 2002, 347: I85-192.

19. Thorand B, Kolb H, Baumert J, Koenig W, Chambless L, Meisinger C, Illig T, Martin S, Herder C: Elevated levels of interleukin- 18 predict the development of type 2 diabetes: results from the MONICA/KORA Augsburg Study, 1984-2002. Diabetes 2005, 54:2932-2938.

20. Holle R, Happich M, Lowel H, Wichmann HE: KORA--a research platform for population based health research. Gesundheitswesen 2005, 67 Suppl I:S19-S25.

21. National Center for Biotechnology Information SNP database dbSNP [http://www.ncbi.nlm.nih.gov/SNP/]

22. Weidinger S, Klopp N, Wagenpfeil S, Rummler L, Schedel M, Kabesch M, Schafer T, Darsow U, Jakob T, Behrendt H, Wichmann HE, Ring J, Illig T: Association of a STAT 6 haplotype with elevated serum IgE levels in a population based cohort of white adults. J Med Genet 2004, 41:658-663.

23. Meisinger C, Thorand B, Schneider A, Stieber J, Doring A, Lowel H: Sex differences in risk factors for incident type 2 diabetes mellitus: the MONICA Augsburg cohort study. Arch Intern Med 2002, 162:82-89.

24. Barlow WE: Robust variance estimation for the case-cohort design. Biometrics 1994, 50:1064-1072.

25. Thorand B, Baumert J, Kolb H, Meisinger C, Chambless L, Koenig W, Herder C: Sex Differences in the Prediction of Type 2 Diabetes by Inflammatory Markers: Results from the MONICA/ KORA Augsburg case-cohort study, 1984-2002. Diabetes Care 2007, 30:854-860.

26. Schaid DJ, Rowland CM, Tines DE, Jacobson RM, Poland GA: Score tests for association between traits and haplotypes when linkage phase is ambiguous. Am J Hum Genet 2002, 70:425-434.

27. $\mathrm{Li} \mathrm{J,} \mathrm{Ji} \mathrm{L}$ : Adjusting multiple testing in multilocus analyses using the eigenvalues of a correlation matrix. Heredity 2005 95:221-227.

28. R Project for Statistical Computing [http://www.R-project.org]

29. Illig T, Bongardt F, Schopfer A, Holle R, Muller S, Rathmann W, Koenig W, Meisinger C, Wichmann HE, Kolb $\mathrm{H}$ : The endotoxin receptor TLR4 polymorphism is not associated with diabetes or components of the metabolic syndrome. Diabetes 2003, 52:286I-2864.

30. Kolek MJ, Carlquist JF, Muhlestein JB, Whiting BM, Horne BD, Bair TL, Anderson JL: Toll-like receptor 4 gene Asp299Gly polymorphism is associated with reductions in vascular inflammation, angiographic coronary artery disease, and clinical diabetes. Am Heart J 2004, I 48: 1034-1040.

31. Rudofsky G Jr., Reismann P, Witte S, Humpert PM, Isermann B, Chavakis T, Tafel J, Nosikov VV, Hamann A, Nawroth P, Bierhaus A Asp299Gly and Thr399lle genotypes of the TLR4 gene are associated with a reduced prevalence of diabetic neuropathy in patients with type 2 diabetes. Diabetes Care 2004, 27: $179-183$.

32. Mohammad MK, Morran M, Slotterbeck B, Leaman DW, Sun Y, Grafenstein H, Hong SC, Mclnerney MF: Dysregulated Toll-like receptor expression and signaling in bone marrow-derived macrophages at the onset of diabetes in the non-obese diabetic mouse. Int Immunol 2006, I 8: I I0I-III3.

33. Song MJ, Kim KH, Yoon JM, Kim JB: Activation of Toll-like receptor $\mathbf{4}$ is associated with insulin resistance in adipocytes. Biochem Biophys Res Commun 2006, 346:739-745.
34. Boekholdt SM, Agema WR, Peters RJ, Zwinderman AH, van der Wall $\mathrm{EE}$, Reitsma PH, Kastelein JJ, Jukema JW: Variants of toll-like receptor 4 modify the efficacy of statin therapy and the risk of cardiovascular events. Circulation 2003, 107:24I6-242I.

35. Castrillo A, Joseph SB, Vaidya SA, Haberland M, Fogelman AM, Cheng G, Tontonoz P: Crosstalk between LXR and toll-like receptor signaling mediates bacterial and viral antagonism of cholesterol metabolism. Mol Cell 2003, I 2:805-8I6.

36. Bjorkbacka H, Kunjathoor VV, Moore KJ, Koehn S, Ordija CM, Lee MA, Means T, Halmen K, Luster AD, Golenbock DT, Freeman MW: Reduced atherosclerosis in MyD88-null mice links elevated serum cholesterol levels to activation of innate immunity signaling pathways. Nat Med 2004, 10:4I6-42I.

\section{Pre-publication history}

The pre-publication history for this paper can be accessed here:

http://www.biomedcentral.com/1471-2350/9/9/prepub
Publish with Bio Med Central and every scientist can read your work free of charge

"BioMed Central will be the most significant development for disseminating the results of biomedical research in our lifetime. "

Sir Paul Nurse, Cancer Research UK

Your research papers will be:

- available free of charge to the entire biomedical community

- peer reviewed and published immediately upon acceptance

- cited in PubMed and archived on PubMed Central

- yours - you keep the copyright
BioMedcentral 